Thomae

Krankenhausplanungsrecht 



\title{
Krankenhaus- planungsrecht
}

von

\author{
Dr. Heike Thomae
}

Rechtsanwältin, Dortmund

2006

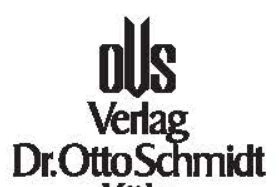

Köln 
Bibliografische Information Der Deutschen Bibliothek

Die Deutsche Bibliothek verzeichnet diese Publikation in der Deutschen Nationalbibliografie; detaillierte bibliografische Daten sind im Internet über $<$ http://dnb.ddb.de $>$ abrufbar.

Verlag Dr. Otto Schmidt KG Gustav-Heinemann-Ufer 58, 50968 Köln

Tel.: 02 21/9 37 38-01, Fax: 02 21/9 37 38-9 43

e-mail:info@otto-schmidt.de www.otto-schmidt.de

ISBN 10: 3-504-04004-1

ISBN 13: 978-3-504-04004-8

\section{(C) 2006 by Verlag Dr. Otto Schmidt KG}

Das Werk einschließlich aller seiner Teile ist urheberrechtlich geschützt. Jede Verwertung, die nicht ausdrücklich vom Urheberrechtsgesetz zugelassen ist, bedarf der vorherigen Zustimmung des Verlags. Das gilt insbesondere für Vervielfältigungen, Bearbeitungen, Übersetzungen, Mikroverfilmungen und die Einspeicherung und Verarbeitung in elektronischen Systemen.

Das verwendete Papier ist aus chlorfrei gebleichten Rohstoffen hergestellt, holz- und säurefrei, alterungsbeständig und umweltfreundlich.

Druck und Verarbeitung: Boyens, Heide

Printed in Germany 